\title{
The Role of Information Technology (IT) in the Economic Development of Palestine
}

\author{
D.O.I - 10.51201/Jusst12570 \\ http://doi.org/10.51201/Jusst12570
}

\begin{abstract}
Issam Ayyash
Department of Computerized Financing and Banking, College of Business and Economics, Palestine Technical University-Kadoorie, Tulkarm, Palestine.
\end{abstract}

\begin{abstract}
Information technology plays vital role in the development of every country. Developed country transformed all they operations but developing counties are still struggling for implementation. The aim of this study is to empirically investigate the impact of information technology in economic development of Palestine. This is quantitative study and the questionnaire was adopted from well reputed studies. The data was collected through convenience sampling and analyzed through multiple regression method by using SPSS. The finding of this study revealed that all hypothesis is accepted. Thus, it can be concluded that all four aspects of IT have positive and significant effect of economic development of the country. This study help manages to understand the importance of IT while decision making. This study help government in policy making. Next study can be conducted on the other aspects of economic development and IT.
\end{abstract}

Keywords: Economic Indicators, Information Technology, Gross Domestic Product.

\section{INTRODUCTION}

Information technology (IT) has become a significant and dominant feature in every aspect for businesses operating globally; it has a major part to play for any field of Business included Supply Chain Management (SCM). Despite the fact the information and communication technology can add value to firm products / services, in order to gain economic development, the adoption rate of new technology in developing countries is relatively low due to low technological and managerial capabilities [1]. A vast number of companies are subcontracting their manufacturing functions to third party manufacturing's companies so that they can focus on their strengths due to increase in competition and the client's expectations [2]. Few Studies have identified that information technology can enhance overall cost, quality of service, productivity, efficiency and effectiveness of manufacturing operations [3].

Information technology has the potential for manufacturing's success that it can help manufacturing's firms to develop to manufacturing's competitiveness and to gain the economic development[4]. Numerous factors have impact the firm's competitiveness. However, most of the researchers since 1980 have examined the concept of IT as a powerful and dominant competitive factor for organization [5]. Second, there is a misunderstanding toward the IT implementation process mainly 
because managers do not understand the relationship between IT and the manufacturing's firms themselves or are ambiguous about the opportunities that IT can offer [6].

\section{LITERATURE REVIEW}

The aim and objective of this research study are to investigate the impact of the information technology on the economic development of the manufacturing's firm in Palestine. The limitation of this study is that it is constraint to the market of Palestine especially of Palestine and data was collected from manufacturing's firm operating in Palestine and relationship between IT and economic developments may not hold in different socio-cultural environments and industrial situations. Secondly, due to time constraint research has not been conducted on a broader spectrum [7] and there are not much secondary studies available on the subject matter based on Palestine scenario. Furthermore, this study is constraints to only four variables of information technology namely; IT Resource Commitment, IT Competency, IT Valence, and last IT Managerial Commitment.

\subsection{Economic Development}

In recent years, the Palestinian economy has been characterized by positive but weakening Gross Domestic Product (GDP) development, high unemployment, and high pressure on real wages' The Palestinian government is burdened by high public debt, especially to the private sector. Private sector development has been stifled by Israeli restrictions on access and movement, as well as other influences associated with the occupation's highly capricious regime[8]. Data from Palestinian firms surveyed in 2006 and again in 2013 showed no significant development in capital investment or employment during this period due to the uncertainty and fragmentation related to Israeli-imposed restrictions.

\subsection{Information Technology}

It has further been reflected that when manufacturing's firm work on IT development and deployment, it results in the achievement of improved performance measures like improved quality of services, reduced cycle time and costs [9]. Considering these findings, it can be reflected that IT has the potential of improving and increasing the economic development of manufacturing's firms across the globe [10] whereas studies have also reflected on the potential of IT to enhance operational effectiveness and efficiency, while bringing a change in the competencies and economic development of these firms [11].

IT resource commitment: For instance, the research conducted by Santhanam and Hartono (2003) argued that IT commitment relies highly on the managerial commitment, which becomes evident when the top management is directly involved within the processes, and shows its support and commitment by allocating sufficient extent and level of resources that may help in the achievement of the desired productivity goals and objectives [12].

IT Competency: In this context, studies in specific reference to manufacturing's industry have reflected that effective IT integration has become a necessity for firms to ensure optimal level of support for the manufacturing's processes and practices [13]. This can be further confirmed through the study offering empirical evidence of IT being fairly predictive of manufacturing's competency. 


\subsection{Research Framework and Hypothesis}

Based on above literature review current study propose a new framework in figure 1 that has four independent variables and one dependent.

H1: IT valence has positive impact on the economic development of Palestine.

H2: IT resource commitment has positive impact on the economic development of Palestine.

H3: IT managerial commitment has positive impact on the economic development of Palestine.

H4: IT competency has positive impact on the economic development of Palestine.

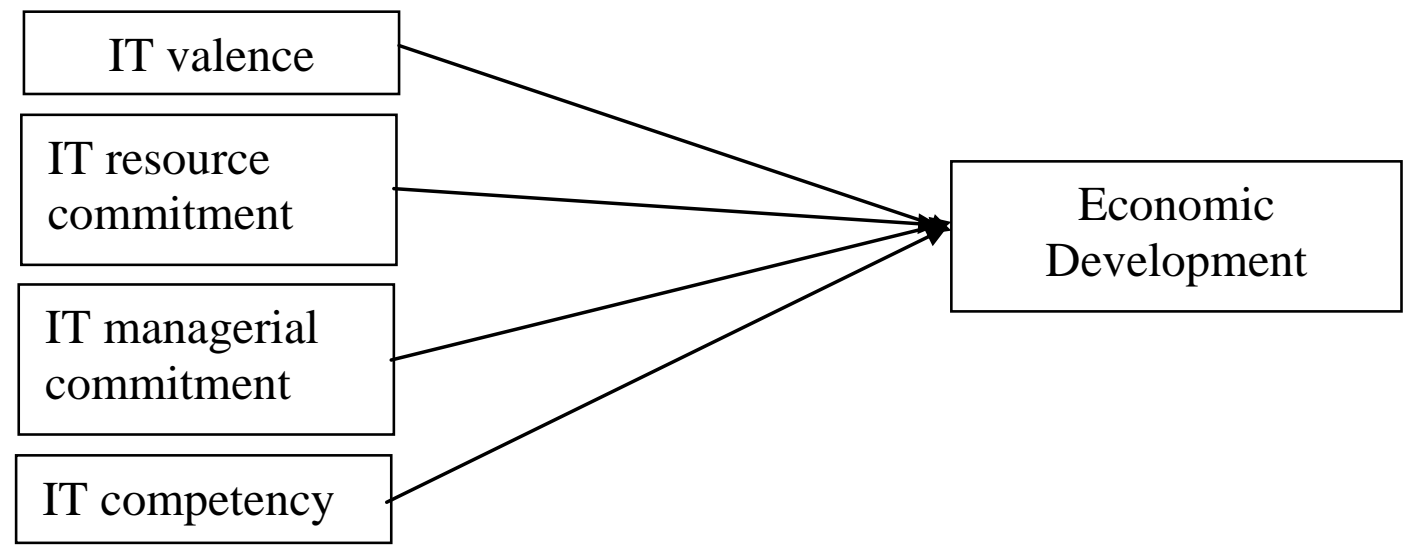

Figure 1: Research Framework

\section{RESEARCH FRAMEWORK}

A research can either be qualitative or quantitative, or both. Qualitative research focuses more on the perceptions and views of the participants, which makes it in-depth and rich method. On the other hand, quantitative method focuses highly on statistical analysis, which makes it more inclined towards empirical investigation [14]. The pathway guiding about the data collection and analysis is reflected under research approach, which is generally in the form of either explanatory or exploratory research [15]. In exploratory research approach, the focus remains on addressing research question by description of the case, which is the reason that this approach is considered when there is insufficient information related to the topic, or when the relationship between variables is not clearly defined [16]. Unlike exploratory research, explanatory research focuses on an in-depth analysis of the topic being investigated, and is ideal to learn more about the future.

\section{ANALYSIS AND DISCUSSION}

\subsection{Descriptive Analysis}

The last general question was about the ownership of the manufacturing's firms. It was found that 87 of the manufacturing's firm operating in Palestine were based on sole proprietorship, 89 of these firms were based on partnership, 105 were foreign joint ventures, 34 were private limited, and 22 were multinational / global manufacturing's firms. 


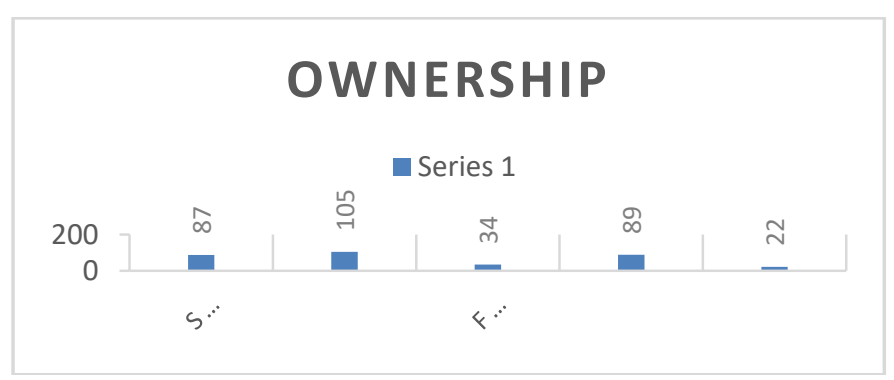

Figure 2: Demographic information

\section{Validity and Reliability}

This study did the face validity. The draft questionnaire was presented to academic expert and industry expert. They have given very fruitfully suggestion [16]. All suggestions and recommendations were incorporated. Meanwhile data reliability was also assessed. It has found that alpha value of all variable is above threshold limit. Thus, it can be concluded that the instrument is valid and reliable.

Table 1: Reliability analysis

\begin{tabular}{|l|c|c|}
\hline \multicolumn{1}{|c|}{ Variable } & No. of items & Cronbach's Alpha \\
\hline IT Valence & 2 & 0.878 \\
\hline Resource effect & 2 & 0.768 \\
\hline Managerial efforts & 2 & 0.699 \\
\hline IT Competency & 2 & 0.899 \\
\hline Economic Development & 7 & 0.711 \\
\hline
\end{tabular}

\subsection{Hypothesis Testing}

Correlation analysis was conducted to identify the relationship between the key factors related to Information Technology, and their relationship with the economic development of manufacturing's firms. The results have been presented [17]. When the IT Valence (ITV) was investigated for its relationship with other variables, it was found that ITV had moderate relationship with RE (0.671) and $\operatorname{ED}(0.623)$, but weak relationship with ME (0.564) and ITC (0.487). However, the nature of the relationship was positive, which was identified through the Sig. (2tailed) value of 0.000 . This means that the relationship ranges from weakly to moderately positive linear relationship [18].

When the Economic development (ED) was investigated for its relationship with other variables, it was found that EDhad moderate relationship with other variables [19]. This was identified through the Pearson Correlation values of 0.623 for ITV, 0.634 for RE, 0.489 for ME, and 0.612 for ITC. The nature of the relationship was positive, which was identified through the Sig. (2-tailed) value of 0.000 . This means that the relationship was moderately positive linear relationship between ED and other variables. 
Table 2: Correlation analysis

\begin{tabular}{|c|c|c|c|c|c|}
\hline & ITV & RE & ME & ITC & ED \\
\hline ITV & 1 & $.671^{* *}$ & $.564^{* *}$ & $.487^{* *}$ & $.623^{* *}$ \\
\hline RE & $.671^{* *}$ & 1 & $.555^{* *}$ & $.489^{* *}$ & $.634^{* *}$ \\
\hline ME & $.564^{* *}$ & $.555^{* *}$ & 1 & $.634^{* *}$ & $.489^{* *}$ \\
\hline ITC & $.487^{* *}$ & $.489^{* *}$ & $.634^{* *}$ & 1 & $.612^{* *}$ \\
\hline ED & $.623^{* *}$ & $.634^{* *}$ & $.489^{* *}$ & $.612^{* *}$ & 1 \\
\hline
\end{tabular}

There is a plethora of studies reflecting on these factors as the source of economic development for a wide range of businesses from different sectors and industries, but the lack of information related to Palestine and its manufacturing's industry has made it difficult to understand the impact of IT on the economic development of manufacturing's firms operating in Palestine. By working on this gap, the research intends to offer valuable knowledge that may help to fill the void in the literature, while helping the manufacturing's firms to understand the value and significance of IT in their operations [20].

Table 3: Regression analysis

\begin{tabular}{|l|c|c|c|}
\hline \multicolumn{1}{|c|}{ Hypothesis } & $\begin{array}{c}\text { Sig. } \\
\text { Value }\end{array}$ & T & $\begin{array}{c}\text { Accepted or } \\
\text { Rejected }\end{array}$ \\
\hline $\begin{array}{l}\text { H1: IT resources commitment has } \\
\text { positive impact on economic } \\
\text { development }\end{array}$ & 0.036 & 2.675 & Accepted \\
\hline $\begin{array}{l}\text { H2: IT competency has positive } \\
\text { impact on economic development }\end{array}$ & 0.000 & 3.312 & Accepted \\
\hline $\begin{array}{l}\text { H3: IT valence has positive impact on } \\
\text { economic development }\end{array}$ & 0.018 & 2.343 & Accepted \\
\hline $\begin{array}{l}\text { H4: IT managerial commitment has } \\
\text { positive impact on economic } \\
\text { development }\end{array}$ & 0.009 & 2.231 & Accepted \\
\hline
\end{tabular}

This section has presented and discussed the results and findings related to the impact of Information Technology on the economic development of manufacturing's firms in Palestine, Palestine. The study confirmed that IT valence, IT resource commitment, IT competency, and IT managerial commitment had significant impact on economic development of manufacturing's firms [21].

The key limitation of this research was the use of quantitative research design, instead of working with mixed method. The quantitative design has provided empirical findings, but if mixed methods had been applied, it would have provided the research with both theoretical and empirical knowledge, which could have added value to the research and its findings [22]. On the other hand, another limitation was the scope of the research. This study has only preferred working with manufacturing's firms in Palestine, which means that the findings and results cannot be generalized, and may hold no value for other sectors [23]. 


\section{CONCLUSION}

In summary, this research has confirmed that Information Technology is critically important for the economic development of manufacturing's firms in Palestine. This was found through different manufacturing's firms operating in Palestine, Palestine via close-ended questionnaire distributed to the firms to be filled and returned. Since there are 480 manufacturing's firms operating in Palestine, this research has only considered 315manufacturing's firms in accordance with the Krejcie \& Morgan (1970) sample size table. The data obtained via questionnaire was used as an input for SPSS, which confirmed that factors related to IT (i.e., IT resource commitment, IT managerial commitment, IT valence and IT competency), had significantly positive impact on economic development.

\section{ACKNOWLEDGMENT}

A special thanks for Palestine Technical University for supporting this research.

\section{REFERENCES}

[1] Napitupulu, D., Syafrullah, M., Rahim, R., Abdullah, D., \& Setiawan, M. I. (2018). Analysis of user readiness toward ICT usage at small medium enterprise in south tangerang. Journal of Physics: Conference Series, 1007(1).

[2] Domingo Galindo, L. (2016). The Challenges of logistics 4.0 for the Supply chain management and the Information Technology (Master's thesis, NTNU).

[3] Zaid, A. A., \& Baig, J. (2020). The Impact of Supply Chain Quality Management Practices, Supply Chain Quality Management Capabilities and Knowledge Transfer on Firm Performance: A Proposed Framework. Paper presented at the The 5th NA International Conference on Industrial Engineering and Operations Management, Detroit, Michigan, USA.

[4] Bhandari, R. (2014). Impact of technology on logistics and supply chain management. IOSR Journal of Business and Management, 2, 17.

[5] Evangelista, P., McKinnon, A., \& Sweeney, E. (2013). Technology adoption in small and medium-sized logistics providers. Industrial Management and Data Systems, 113(7), 967-989.

[6] Fadiah, N., Mohd, B., Wahab, S. A., Mamun, A. Al, Ahmad, G. Bin, \& Fazal, S. A. (2017). Logistics Capability, Information Technology, and Innovation Capability of Logistics Service Providers: Empirical Evidence from East Coast Malaysia. International Review of Management and Marketing, 7(1), 326-336.

[7] Arqawi, S. M, \& Zaid, A. A. (2020). The impact of Total Quality Management on the Institution Performance mediating role of Knowledge Management. International Journal of Advanced Science and Technology, $29(7 s), 5269-5277$.

[8] Saleh, M.W.A., Zaid, M.A.A., Shurafa, R., Maigoshi, Z.S., Mansour, M. \& Zaid, A. (2021). Does board gender enhance Palestinian firm performance? The moderating role of corporate social responsibility. Corporate Governance, Emerald Publishing Limited. doi.org/10.1108/CG08-2020-0325. 
[9] Gunasekaran, A., Subramanian, N., \& Papadopoulos, T. (2017). Information technology for competitive advantage within logistics and supply chains: A review. Transportation Research Part E: Logistics and Transportation Review, 99, 14-33.

[10] Baig, J., \& Zaid, A. A. (2020). Behavioral Incivility and Leadership Styles: Assessing The Mediation of Job Strain, Employment Insecurity and Relational Injustice: A Conceptual Model. International Journal of Scientific \& Technology Research, 9(3), 687-693.

[11] Zaid, A. A., Arqawi, S. M., Mwais, R. M. A., Al Shobaki, M. J., \& AbuNaser, S. S. (2020). The Impact of Total Quality Management and Perceived Service Quality on Patient Satisfaction and Behavior Intention in Palestinian Healthcare Organizations. Technology Reports of Kansai University, 62(3), 221-232.

[12] Kang, L., Tan, C.-H., \& Zhao, J. L. (2018). Organizational Quest for Competitive Advantage through Innovation: Where Should IT Capability be Focused? Paper presented at the Twenty-Second Pacific Asia Conference on Information Systems (PACIS), Japan.

[13] Kumar, V., Amorim, M., Bhattacharya, A., Garza-Reyes, J. A., Beh, L. S., Ghobadian, A.,\& O'Regan, N. (2016). Second-life retailing: a reverse supply chain perspective. Supply Chain Management: An International Journal.

[14] Ahmad Shwekeh, Ahmed Zaid, Mohammed W. A. Saleh3 \& Marwan Mohammad Mansour (2021). The Impact of Economic Indicators on Food Supply Chain of Palestine. Journal of University of Shanghai for Science and Technology, 23(1), 264-275. D.O.I - 10.51201/Jusst12555.

[15] Morgan, T. R., Richey Jr, R. G., \& Autry, C. W. (2016). Developing a reverse logistics competency: the influence of collaboration and information technology. International Journal of Physical Distribution \& Logistics Management, 46(3), 293-315.

[16] Saleh, M.W., Latif, R.A., Bakar, F.A. and Maigoshi, Z.S. (2020). The impact of multiple directorships, board characteristics, and ownership on the performance of Palestinian listed companies. International Journal of Accounting, Auditing and Performance Evaluation. 16(4), 63-80. DOI 10.1504/IJAAPE.2020.106774.

[17] Saleh, M. W., Shurafa, R., Shukeri, S. N., Nour, A. I., \& Maigosh, Z. S. (2020). The effect of board multiple directorships and CEO characteristics on firm performance: evidence from Palestine. Journal of Accounting in Emerging Economies. 10(4), 637-654. DOI 10.1108/JAEE-12-2019-0231.

[18] Namada, J. M. (2018). Organizational learning and competitive advantage. In Handbook of Research on Knowledge Management for Contemporary Business Environments (pp. 86-104). IGI Global.

[19] Neirotti, P., \& Raguseo, E. (2017). On the contingent value of IT-based capabilities for the competitive advantage of SMEs: Mechanisms and empirical evidence. Information \& Management, 54(2), 139-153.

[20] Okundaye, K., Fan, S. and Dwyer, R. (2019), "Impact of information and communication technology in Nigerian small-to medium-sized enterprises", Journal of Economics, Finance and Administrative Science, Vol. 24 No. 47, pp. 29-46. 
[21] Baig, J., Soon, N. K., \& Andleeb, N. (2019). Psychological Factors for Organizational Health. Indian Journal of Public Health Research \& Development, 10(6), 1412-1415.

[22] Shanker, S., Rashid, U. K., Mohamed Zabri, S., Ahmad, K., \& Baig, J. (2018). A conceptual paper on determinants of financial sustainability among small and medium enterprises in Malaysia. Journal for Studies in Management and Planning, 4(13), 313-320.

[23] Shahbaz, M. S., Othman, B. A., Salman, P. M., Memon, D. A., \& Rasi, R. Z. B. R. (2020). A Proposed Conceptual Action Plan for Identification, Assessment and Mitigation of Supply Chain Risks. Int. J. Advanced Operations Management, 12(1), 65-80. 